OPEN ACCESS

Edited by:

Hu Li,

Guizhou University, China

Reviewed by:

Shima Liu,

Jishou University, China

Yulin $\mathrm{Hu}$,

University of Prince Edward Island,

Canada

${ }^{*}$ Correspondence:

Can $\mathrm{Li}$

lican790108@163.com

₹ORCID ID:

Hangyu Luo,

orcid.org/0000-0002-4188-7221

${ }^{t}$ These authors have contributed equally to this work

Specialty section:

This article was submitted to Green and Sustainable Chemistry,

a section of the journal

Frontiers in Chemistry

Received: 08 December 2021 Accepted: 27 December 2021

Published: 31 January 2022

Citation:

Liu X, Yu D, Luo H and Li C (2022) Catalytic Upgrading of Lignocellulosic Biomass Sugars Toward Biofuel 5Ethoxymethylfurfural.

Front. Chem. 9:831102.

doi: 10.3389/fchem.2021.831102

\section{Catalytic Upgrading of Lignocellulosic Biomass Sugars Toward Biofuel 5-Ethoxymethylfurfural}

\author{
Xiaofang $\mathrm{Liu}^{\dagger}$, Dayong $\mathrm{Yu}^{\dagger}$, Hangyu $\mathrm{Luo}^{\ddagger}$ and Can $\mathrm{Li}^{*}$ \\ Guizhou Provincial Key Laboratory for Rare Animal and Economic Insects of the Mountainous Region, College of Biology and \\ Environmental Engineering, Guiyang University, Guiyang, China
}

The conversion of biomass into high-value chemicals through biorefineries is a requirement for sustainable development. Lignocellulosic biomass (LCB) contains polysaccharides and aromatic polymers and is one of the important raw materials for biorefineries. Hexose and pentose sugars can be obtained from LCB by effective pretreatment methods, and further converted into high-value chemicals and biofuels, such as 5-hydroxymethylfurfural (HMF), levulinic acid (LA), $\gamma$-valerolactone (GVL), ethyl levulinate (EL), and 5-ethoxymethylfurfural (EMF). Among these biofuels, EMF has a high cetane number and superior oxidation stability. This mini-review summarizes the mechanism of several important processes of EMF production from LCB-derived sugars and the research progress of acid catalysts used in this reaction in recent years. The influence of the properties and structures of mono- and bi-functional acid catalysts on the selectivity of EMF from glucose were discussed, and the effect of reaction conditions on the yield of EMF was also introduced.

Keywords: lignocellulosic biomass, biorefinery, high-value chemicals, biofuels, 5-ethoxymethylfurfural

\section{INTRODUCTION}

Extensive use of fossil fuels has caused energy depletion and serious environmental problems (e.g., greenhouse effect and acid rain). It is urgent to develop green renewable energy to replace fossil fuels for a better living environment (Li et al., 2017; Li et al., 2020; Pan et al., 2020). Lignocellulosic biomass (LCB) is a typical renewable energy with an annual global output of approximately 12 billion tons (Abraham et al., 2020). It is mainly composed of a layer of firm lignin-wrapped cellulose and hemicellulose components (Bhatia et al., 2020). Among them, cellulose is a biopolymer linking massive glucose units via $\beta$-1,4-glycosidic bonds, accounting for 38-50 wt\% of LCB (Somerville et al., 2010). Thus, a large amount of glucose can be obtained by hydrolyzing cellulose. There were many researchers focused on the conversion of glucose to high value-added chemicals. Through various catalytic reactions such as dehydration, hydrogenation, hydrolysis, alcoholysis, and etherification, glucose can be turned into high value-added fuels and fine chemicals [e.g., 5-hydroxymethylfurfural (HMF), 5-ethoxymethylfurfural (EMF), levulinic acid (LA), and ethyl levulinate (EL)] (Rackemann and Doherty, 2011; Yang et al., 2012; Climent et al., 2014; Yang et al., 2019).

Furan derivatives like furfural, furfuryl alcohol, HMF, EMF, and 2,5-dimethylfuran have shown great potential in the formation of fine chemicals and alternative fossil fuels (Tong et al., 2010; Liu et al., 2021). Among these furan derivatives, EMF has the advantages for instance a higher boiling point $\left(235^{\circ} \mathrm{C}\right)$, superior energy density $(30.3 \mathrm{MJ} / \mathrm{L})$ compare with ethanol $(23.5 \mathrm{MJ} / \mathrm{L})$, and low flash point (ca. $110^{\circ} \mathrm{C}$ ) (Corma et al., 2007). Therefore, it has been considered one of the excellent choices of fuel additives in the future (Li et al., 2016). When $17 \mathrm{wt} \% \mathrm{EMF}$ was used as an additive that mixes 


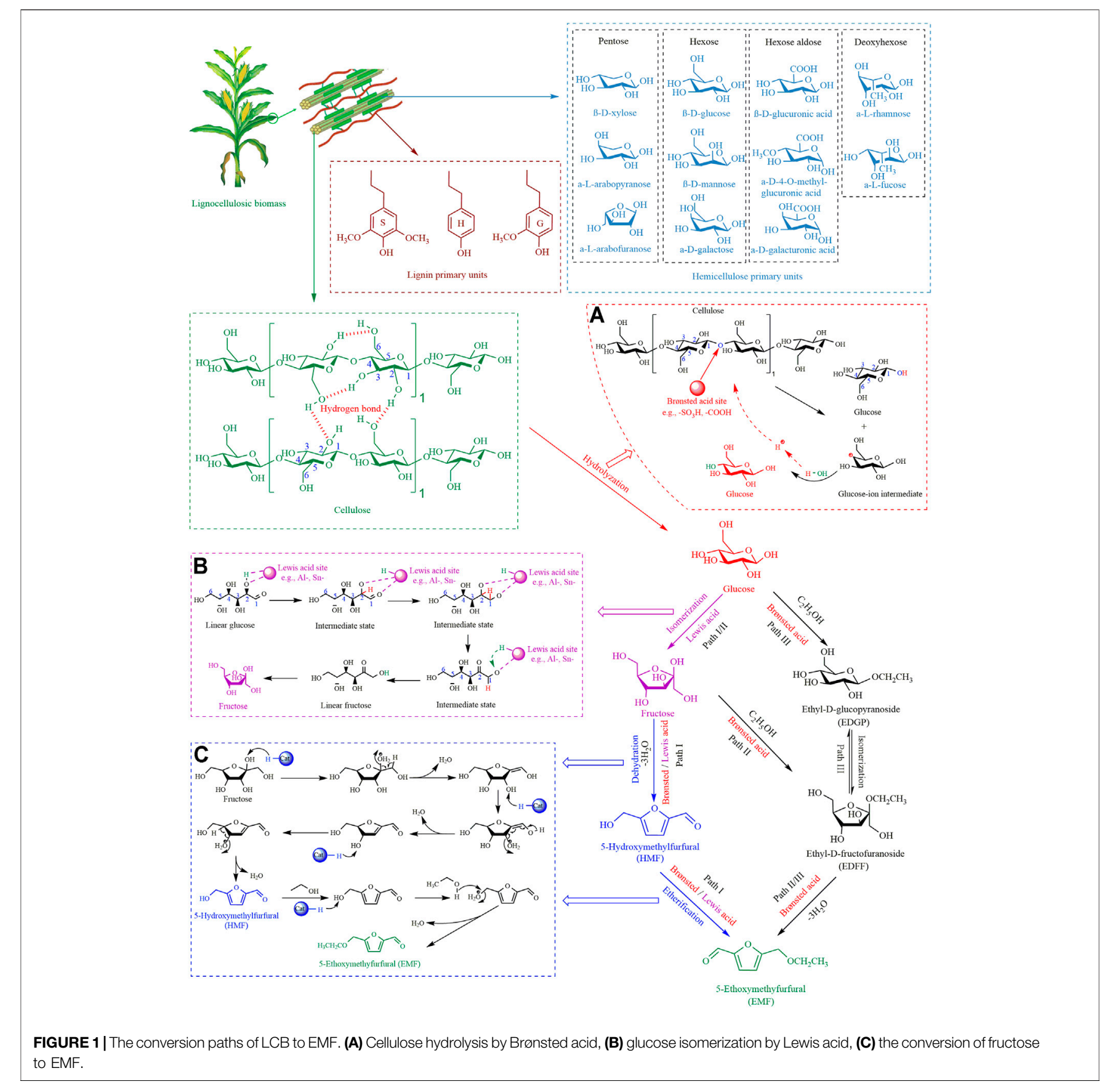

with fuel in a fuel engine, the engine could run stably and release fewer harmful particles and sulfides (with a $16 \%$ reduction in soot) (Mascal and Nikitin, 2008). In addition, EMF has also be used as a reaction substrate for the synthesis of various industrially significant chemicals, such as 5-ethoxymethylfurfuryl alcohol, 2,5-diethoxymethylfuran, and cyclopentenone (Ras et al., 2009; Ras et al., 2010; Bredihhin et al., 2016).

Generally, EMF can be transformed from HMF and ketose (e.g., fructose, inulin, and sucrose) with a satisfactory yield (ca. 70-90\%) (Bredihhin et al., 2013; Dai et al., 2019; Hafizi et al., 2020). Yet, the industrial-scale production of EMF was limited by these high-priced feedstocks. For example, the price of HMF and fructose in Sigma-Aldrich is 12,634 and 205 EUR per kilogram, respectively. However, glucose has a lower price (88 EUR per kilogram in Sigma-Aldrich), which is reasonable to convert glucose into EMF (187 EUR per gram in Sigma-Aldrich). Moreover, the large amount of glucose can be obtained from cheap LCB, which is also a choice for economic and environmental development. At present, relevant reviews have summarized the use of various types of catalysts to convert different raw materials into EMF (Chen B. et al., 2020; Yu et al., 2021). But almost no review focused on the mechanism 
of EMF synthesis from glucose to EMF. Hereby, this mini-review introduces the paths and mechanisms of producing EMF from LCB derivatives, with a focus on challenges of the conversion of glucose to EMF. The aim is to provide a feasibility method for maximizing the conversion of LCB into EMF.

\section{THE PREPARATION OF EMF FROM LCB-DERIVED SUGARS}

\section{The Synthesis Routes}

EMF can be obtained from glucose or cellulose via multi-step chemical conversion (Zheng et al., 2021). There are three paths to synthesize EMF from glucose (Figure 1). The mainstream Path I uses glucose as the starting material, which is isomerized to produce fructose, then $\mathrm{HMF}$ is obtained through fructose dehydration $\left(-3 \mathrm{H}_{2} \mathrm{O}\right)$, and finally, HMF is etherified to EMF (Chen et al., 2019). The most important step in this path is the isomerization of glucose, which usually requires the participation of Lewis acid (Lew et al., 2012). There are two other secondary paths with ethyl-D-fructofuranoside (EDFF) as an intermediate transit. Path II is that fructose reacts with ethanol in acidic solution to form EDFF, which is then dehydrated $\left(-3 \mathrm{H}_{2} \mathrm{O}\right)$ to produce EMF (Zhang et al., 2018). Path III is glucose and ethanol to generate ethyl-D-glucopyranoside (EDGP) in an acid medium, then isomerized to EDFF, finally dehydrated $\left(-3 \mathrm{H}_{2} \mathrm{O}\right)$ to obtain EMF (Zheng et al., 2021). Currently, most EMF is obtained through Path I for the following reasons:

(i) Compare Path I and Path II. The difference is that fructose is more likely to be converted into HMF (Path I) or EDFF (Path II). It has been found that fructose was inclined to be dehydrated to form HMF (Path I) rather than etherified with ethanol to form EDFF (Path II) when Brønsted acid is present (Xiang et al., 2017).

(ii) Compare Path I and Path III. Glucose is usually isomerized to fructose when Brønsted acid and Lewis acid are present at the same time (He et al., 2022). When there is only Brønsted acid in the system, although the DFT calculation results show that the highest energy barriers required for Path I $(17.7 \mathrm{kcal} / \mathrm{mol})$ and II $(20.8 \mathrm{kcal} / \mathrm{mol})$ are similar, the thermodynamic reaction is more favorable for Path I (Wang et al., 2021). And the intermediate EDGP in Path III is difficult to continue further conversion.

\section{The Synthesis Mechanism}

The conversion of cellulose to EMF requires multiple reaction processes, namely cascade reactions. A detailed description of the synthesis mechanism of each step in Path I is shown in Figure 1.

Cellulose has a condensed structure (Figure 1), and is a high molecular polymer connected by $\beta$-1,4-glycosidic bonds and axial hydrogen bonds between numerous glucose monomers (Shrotri et al., 2018). Therefore, the hydrolysis of cellulose in the first step of Path I is a major obstacle that needs to be overcome. Many studies have shown that Brønsted acid can destroy the $\beta-1,4$ glycosidic bonds of cellulose (Zeng and Pan, 2020). As shown in Figure 1A, firstly, the oxygen atom of the $\beta$-1,4-glycosidic bond is attacked by the proton of the Brønsted acid site. Then the C-O bond between the two glucose molecules is broken for releasing glucose and glucose-ion intermediate. Finally, the hydroxyl group from water binds to the exposed carbon of glucose-ion intermediate to form glucose. And the free protons from water participate in the next hydrolysis reaction.

The second step in Path I, the isomerization of glucose into fructose, is the most important step in determining the yield of EMF. Many studies have indicated that glucose transforms into fructose via Lewis acid sites (Li et al., 2014; Rajabbeigi et al., 2014). As shown in Figure 1B, the $\mathrm{C}_{1}-\mathrm{O}_{5}$ bond of glucose is broken by Lewis acid and forms a linear glucose molecule. The oxygen atoms of $\mathrm{C}_{1}$ and $\mathrm{C}_{2}$ on linear glucose coordinate with the Lewis acid center. Subsequently, the hydrogen on $\mathrm{C}_{2}$ is transferred to $\mathrm{C}_{1}$, which realizes the aldehyde-ketone conversion between $\mathrm{C}_{1}$ and $\mathrm{C}_{2}$ to form linear fructose. Finally, the oxygen of $\mathrm{C}_{2}$ is linked with $\mathrm{C}_{5}$ to form a fructose molecule by $\mathrm{C}-\mathrm{C}$ bond.

The third step is that fructose generates HMF by dehydration of three $\mathrm{H}_{2} \mathrm{O}$ molecules under acidic conditions. Firstly, the hydroxyl group on $\mathrm{C}_{2}$ is protonated to release the first $\mathrm{H}_{2} \mathrm{O}$, and $\mathrm{C}=\mathrm{C}$ is formed between $\mathrm{C}_{1}$ and $\mathrm{C}_{2}$. Then, the hydroxyl group on $\mathrm{C}_{3}$ is protonated to release the second $\mathrm{H}_{2} \mathrm{O}$. Meanwhile, the $\mathrm{C}=\mathrm{C}$ bond between $\mathrm{C}_{1}$ and $\mathrm{C}_{2}$ is broken, the aldehyde group is formed at the $\mathrm{C}_{1}$, and $\mathrm{C}=\mathrm{C}$ is formed between $\mathrm{C}_{2}$ and $\mathrm{C}_{3}$. Finally, the hydroxyl group on $\mathrm{C}_{4}$ is protonated to release the third $\mathrm{H}_{2} \mathrm{O}$, and $\mathrm{C}=\mathrm{C}$ is formed between $\mathrm{C}_{4}$ and $\mathrm{C}_{5}$ to get HMF. After that, HMF is etherified to EMF with ethanol existence (Figure 1C).

\section{THE FACTORS IMPACTING THE YIELD OF EMF FROM LCB-DERIVED SUGARS}

Many LCB-derived sugars and compounds have been used to convert into EMF, such as cellulose, cellobiose, and glucose. The EMF yield from these substrates has displayed the order of glucose > cellobiose > cellulose > LCB (Li et al., 2016; Guo et al., 2018). In general, only moderate or low EMF yields can be obtained from these raw materials which are due to the different number of reaction steps. For example, HMF as a feedstock (high EMF yield) just needs one step, but cellulose (low EMF yield) needs four steps. Meanwhile, the lengthy chemical reaction process increased more by-products or humins (Zheng et al., 2021). Therefore, many studies were devoted to developing more efficient catalytic systems, which can obtain more satisfactory EMF yields from glucose or glucose-based carbohydrates (Guo et al., 2017; Guo et al., 2018; Karnjanakom et al., 2020; He et al., 2022). Some catalysts and reaction conditions for obtaining EMF from LCB-derived sugars were summarized in Table 1.

\section{Monofunctional Acid Catalysts}

Currently, many monofunctional (Brønsted or Lewis) acid catalysts are designed to catalyze the synthesis of EMF from glucose, including $\mathrm{H}_{2} \mathrm{SO}_{4}$ (Xu et al., 2017), metal salts (Liu et al., 2013), $\mathrm{SO}_{3} \mathrm{H}$-based catalyst (Liu and Zhang, 2013), and ionic liquid (Guo et al., 2017). From the perspective of the synthesis routes, theoretically, when only Brønsted acid exists, using glucose as substrates hardly produces EMF. Yet, many studies had found that in the presence of Brønsted acid, a spot of EMF could be detected using glucose $(7.46 \%$ yield), cellobiose $(19.8 \%$ yield), and cellulose (3.05\% yield) as raw materials (De et al., 2012; 
TABLE 1 | EMF from LCB-derived sugars via different catalysts and reaction systems.

\begin{tabular}{|c|c|c|c|c|c|c|c|c|}
\hline Entry & Feedstock & Catalyst & $\begin{array}{l}\text { Brønsted } \\
\text { acid }\end{array}$ & $\begin{array}{l}\text { Lewis } \\
\text { acid }\end{array}$ & Solvent & $\begin{array}{l}\text { Reaction } \\
\text { conditions }\end{array}$ & $\begin{array}{c}\text { Yield/ } \\
\%\end{array}$ & Ref. \\
\hline 1 & Glucose & $\mathrm{H}_{2} \mathrm{SO}_{4}$ & $-\mathrm{SO}_{3} \mathrm{H}$ & - & Ethanol & $200^{\circ} \mathrm{C}, 90 \mathrm{~min}$ & 7.5 & Xu et al. (2017) \\
\hline 2 & Glucose & {$[\mathrm{BMIM}]\left[\mathrm{HSO}_{4}\right]$} & $-\mathrm{SO}_{3} \mathrm{H}$ & - & Ethanol & $130^{\circ} \mathrm{C}, 20 \mathrm{~min}$ & 8.0 & Guo et al. (2017) \\
\hline 3 & Glucose & $\mathrm{AlCl}_{3}$ & - & Al- & Ethanol & $100^{\circ} \mathrm{C}, 11 \mathrm{~h}$ & 38.4 & Liu et al. (2013) \\
\hline 4 & Corn Stover & USY & $\mathrm{Al}-\mathrm{O}(\mathrm{H})-\mathrm{Si}$ & Al- & $\begin{array}{c}\text { Ethanol/THF }(\mathrm{v} / \mathrm{v}= \\
1: 1)\end{array}$ & $168^{\circ} \mathrm{C}, 2.9 \mathrm{~h}$ & 21.8 & Chen et al. (2019) \\
\hline 5 & Glucose & DeAl-H- $\beta$ & $\mathrm{Al}-\mathrm{O}(\mathrm{H})-\mathrm{Si}$ & Al- & Ethanol & $125^{\circ} \mathrm{C}, 10 \mathrm{~h}$ & 41.0 & Li et al. (2016) \\
\hline 6 & Glucose & MFI-Sn/Al & $\mathrm{Al}-\mathrm{O}(\mathrm{H})-\mathrm{Si}$ & $\mathrm{Sn}-/ \mathrm{Al}-$ & Ethanol & $140^{\circ} \mathrm{C}, 9 \mathrm{~h}$ & 44.0 & Bai et al. (2018) \\
\hline 7 & Glucose & BFC-3 & $-\mathrm{SO}_{3} \mathrm{H}$ & Cr- & $\begin{array}{c}\text { Ethanol/THF }(\mathrm{v} / \mathrm{v}= \\
3: 2)\end{array}$ & $100^{\circ} \mathrm{C}, 10 \mathrm{~h}$ & 48.1 & Chen et al. (2020a) \\
\hline 8 & Cellobiose & BFC-3 & $-\mathrm{SO}_{3} \mathrm{H}$ & Cr- & $\begin{array}{c}\text { Ethanol/THF }(\mathrm{v} / \mathrm{v}= \\
3: 2)\end{array}$ & $100^{\circ} \mathrm{C}, 10 \mathrm{~h}$ & 37.1 & Chen et al. (2020b) \\
\hline 9 & Glucose & Zr-Sn-Fe-Al-O-S & $-\mathrm{SO}_{3} \mathrm{H}$ & $\begin{array}{l}\mathrm{Zr}-/ \mathrm{Sn}-/ \\
\mathrm{Fe}-/ \mathrm{Al}-\end{array}$ & Ethanol & $160^{\circ} \mathrm{C}, 12 \mathrm{~h}$ & 0.7 & He et al. (2022) \\
\hline 10 & Glucose & Zr-Sn-Fe-Al-O-S & $-\mathrm{SO}_{3} \mathrm{H}$ & $\begin{array}{l}\mathrm{Zr}-/ \mathrm{Sn}-/ \\
\mathrm{Fe}-/ \mathrm{Al}-\end{array}$ & $\begin{array}{l}\text { Ethanol/DMSO (v/v } \\
=9: 1)\end{array}$ & $160^{\circ} \mathrm{C}, 4 \mathrm{~h}$ & 3.9 & He et al. (2022) \\
\hline 11 & Glucose & Zr-Sn-Fe-Al-O-S & $-\mathrm{SO}_{3} \mathrm{H}$ & $\begin{array}{l}\mathrm{Zr}-/ \mathrm{Sn}-/ \\
\mathrm{Fe}-/ \mathrm{Al}-\end{array}$ & $\begin{array}{l}\text { Ethanol/DMSO (v/v } \\
=9: 1)\end{array}$ & $160^{\circ} \mathrm{C}, 12 \mathrm{~h}$ & 7.9 & He et al. (2022) \\
\hline 12 & Glucose & $\mathrm{Zr}-\mathrm{Sn}-\mathrm{Fe}-\mathrm{Al}-\mathrm{O}-\mathrm{S}$ & $-\mathrm{SO}_{3} \mathrm{H}$ & $\begin{array}{l}\mathrm{Zr}-/ \mathrm{Sn}-/ \\
\mathrm{Fe}-/ \mathrm{Al}-\end{array}$ & $\begin{array}{l}\text { Ethanol/DMSO (v/v } \\
=3: 1)\end{array}$ & $160^{\circ} \mathrm{C}, 12 \mathrm{~h}$ & 14.3 & He et al. (2022) \\
\hline 13 & Glucose & $\mathrm{Zr}-\mathrm{Sn}-\mathrm{Fe}-\mathrm{Al}-\mathrm{O}-\mathrm{S}$ & $-\mathrm{SO}_{3} \mathrm{H}$ & $\begin{array}{l}\mathrm{Zr}-/ \mathrm{Sn}-/ \\
\mathrm{Fe}-/ \mathrm{Al}-\end{array}$ & $\begin{array}{l}\text { Ethanol/DMSO (v/v } \\
=1: 1)\end{array}$ & $160^{\circ} \mathrm{C}, 12 \mathrm{~h}$ & 33.1 & He et al. (2022) \\
\hline 14 & Glucose & $\mathrm{Zr}-\mathrm{Sn}-\mathrm{Fe}-\mathrm{Al}-\mathrm{O}-\mathrm{S}$ & $-\mathrm{SO}_{3} \mathrm{H}$ & $\begin{array}{l}\mathrm{Zr}-/ \mathrm{Sn}-/ \\
\mathrm{Fe}-/ \mathrm{Al}-\end{array}$ & $\begin{array}{c}\text { Ethanol/DMSO (v/v } \\
=1: 3)\end{array}$ & $160^{\circ} \mathrm{C}, 12 \mathrm{~h}$ & 12.4 & He et al. (2022) \\
\hline 15 & Glucose & $\mathrm{Zr}-\mathrm{Sn}-\mathrm{Fe}-\mathrm{Al}-\mathrm{O}-\mathrm{S}$ & $-\mathrm{SO}_{3} \mathrm{H}$ & $\begin{array}{l}\mathrm{Zr}-/ \mathrm{Sn}-/ \\
\mathrm{Fe}-/ \mathrm{Al}-\end{array}$ & $\begin{array}{l}\text { Ethanol/DMSO (v/v } \\
=1: 1)\end{array}$ & $140^{\circ} \mathrm{C}, 12 \mathrm{~h}$ & 18.8 & He et al. (2022) \\
\hline 16 & Glucose & $\mathrm{Zn}-\mathrm{S}-\mathrm{C}$ & $-\mathrm{SO}_{3} \mathrm{H}$ & Zn- & $\begin{array}{c}\text { Ethanol/THF }(\mathrm{v} / \mathrm{v}= \\
1: 1)\end{array}$ & $\begin{array}{l}\text { Ultrasonic system: } 98^{\circ} \mathrm{C} \text {, } \\
\qquad 47 \mathrm{~min}\end{array}$ & 80.9 & Karnjanakom et al. (2020) \\
\hline 17 & Cellobiose & $\mathrm{Zn}-\mathrm{S}-\mathrm{C}$ & $-\mathrm{SO}_{3} \mathrm{H}$ & $\mathrm{Zn}-$ & $\begin{array}{c}\text { Ethanol/THF }(v / v= \\
1: 1)\end{array}$ & $\begin{array}{l}\text { Ultrasonic system: } 98^{\circ} \mathrm{C} \\
47 \mathrm{~min}\end{array}$ & 74.6 & Karnjanakom et al. (2020) \\
\hline 18 & Glucose & $\begin{array}{l}\mathrm{Zn}-\mathrm{SO}_{3} \mathrm{H}-\mathrm{GR}- \\
\quad \text { carbon }\end{array}$ & $-\mathrm{SO}_{3} \mathrm{H}$ & $\mathrm{Zn}-$ & $\begin{array}{c}\text { Ethanol/THF }(\mathrm{v} / \mathrm{v}= \\
1: 2)\end{array}$ & $\begin{array}{l}\text { Ultrasonic system: } 106^{\circ} \mathrm{C} \text {, } \\
\qquad 72 \mathrm{~min}\end{array}$ & 86.3 & $\begin{array}{l}\text { Karnjanakom and Maneechakr, } \\
\text { (2019a) }\end{array}$ \\
\hline 19 & Glucose & Al-SC & $-\mathrm{SO}_{3} \mathrm{H}$ & Al- & $\begin{array}{c}\text { Ethanol/THF }(\mathrm{v} / \mathrm{v}= \\
1: 1)\end{array}$ & $\begin{array}{l}\text { Ultrasonic system: } 106^{\circ} \mathrm{C} \\
72 \mathrm{~min}\end{array}$ & 84.4 & $\begin{array}{l}\text { Karnjanakom and Maneechakr, } \\
\text { (2019b) }\end{array}$ \\
\hline 20 & Glucose & Zn-SC & $-\mathrm{SO}_{3} \mathrm{H}$ & $\mathrm{Zn}-$ & $\begin{array}{c}\text { Ethanol/THF }(\mathrm{v} / \mathrm{V}= \\
1: 1)\end{array}$ & $\begin{array}{l}\text { Ultrasonic system: } 106^{\circ} \mathrm{C} \\
72 \mathrm{~min}\end{array}$ & 85.1 & $\begin{array}{l}\text { Karnjanakom and Maneechakr, } \\
\text { (2019b) }\end{array}$ \\
\hline
\end{tabular}

Guo et al., 2017; Xu et al., 2017). One possible reason for this is that glucose formed a bit intermediate 3-deoxyglucosone in Brønsted acid, which is then dehydrated to form HMF, and finally etherified to EMF (Jadhav et al., 2011; Jadhav et al., 2012). In addition, Brønsted acid and protonated ethanol $\left(\left[\mathrm{C}_{2} \mathrm{H}_{5} \mathrm{OH}_{2}\right]^{+}\right)$ can open the ring of glucose to form intermediate 1,2-enediol then isomerizes to fructose, which makes it possible to produce EMF in the next step (Guo et al., 2017; Wang et al., 2021). When there is only Lewis acid in the system, a moderate EMF yield (10-40\%) can be obtained from glucose (Dutta et al., 2012; Liu et al., 2013; Tan et al., 2017). In the presence of a single Lewis acid, the possible reason for the failure to obtain high EMF yield is that the Lewis acid cannot provide $\mathrm{H}^{+}$, resulting in the low $\left[\mathrm{C}_{2} \mathrm{H}_{5} \mathrm{OH}_{2}\right]^{+}$concentration in the system which limits the fructose dehydration and subsequent etherification steps. Meanwhile, the EMF yields obtained by catalyzing glucose with different types of metal salts were quite different. Such as metal chlorides $\mathrm{AlCl}_{3}$ and $\mathrm{CrCl}_{3}$ could obtain 11.2 and $15.2 \%$ EMF yields, respectively. However, with metal sulfates $\mathrm{Al}_{2}\left(\mathrm{SO}_{4}\right)_{3}$, $\mathrm{CuSO}_{4}, \mathrm{Fe}_{2}\left(\mathrm{SO}_{4}\right)_{3}$, and $\mathrm{Cr}_{2}\left(\mathrm{SO}_{4}\right)_{3}$ as catalysts, the reaction system hardly detected EMF, but more EDGP (ca. 80\% yield) was detected (Yu et al., 2017). Thus, the metal chloride is more conducive to the isomerization of glucose, while the metal sulfate is more inclined to promote the etherification of glucose. Overall, the monofunctional acid catalysts cannot obtain satisfactory EMF yield from glucose. Whereas, the developed bifunctional acid catalysts with Brønsted-Lewis acids can obtain high EMF yield from glucose.

\section{Bifunctional Acid Catalysts}

Generally, zeolite molecular sieve catalysts contain Brønsted acid species $\mathrm{Al}-\mathrm{O}(\mathrm{H})-\mathrm{Si}$ (framework four-coordinate aluminum), and Lewis acid species Al- (framework three-coordinate aluminum) can be obtained after high-temperature dealumination (Xin et al., 2019). For example, ultra-stable Y zeolite (USY) and $\beta$ zeolite ( $\mathrm{H}$ $\beta$ ) after high-temperature dealumination were used to catalyze the synthesis of EMF from glucose and obtained 39.5 and $41 \%$ EMF yields, respectively (Li et al., 2016; Zheng et al., 2021). In addition, zeolite can also be modified to obtain better EMF yield. Introducing Lewis acid species Sn- and Al- into zeolite to obtain MFI-Sn/Al (Bai et al., 2018) or simultaneously introduce $\mathrm{H}_{4}$ $\left[\mathrm{Si}\left(\mathrm{W}_{3} \mathrm{O}_{10}\right)_{4}\right]$ and $\mathrm{SnCl}_{4}$ (Brønsted-Lewis acids) into zeolite to obtain SBA-15 (Srinivasa Rao et al., 2020). These catalysts could obtain EMF with medium yield from glucose. A soft template 
HIPE was utilized to support the sulfonic acid group and $\mathrm{Cr}^{3+}$ to synthesize BFC-3 catalyst, which could be used to catalyze glucose and cellobiose and obtain 48.1 and 37.1\% EMF yields, respectively (Chen et al., 2020a). Furthermore, glycerol and glucose were sulfonated into carbon spheres, then introduced into $\mathrm{Zn}$ - to prepare $\mathrm{Zn}-\mathrm{SO}_{3} \mathrm{H}-\mathrm{GR}$-carbon (Karnjanakom and Maneechakr, 2019a) and Zn-S-C (Karnjanakom et al., 2020). Both of them can obtain amazing EMF yields from glucose (86.3 and 80.9\%).

Bifunctional acid catalysts have great differences in catalytic performance. Using the same Brønsted acid and different Lewis acids to prepare various catalysts, the yields of EMF obtained from glucose were different. For example, the sulfonated carbon (SC) was doped with different metal species ( $\mathrm{Zn-}, \mathrm{Al}-$, and $\mathrm{Ni}$-), which exhibits different catalytic performances (Karnjanakom and Maneechakr, 2019b). When EMF was selectively produced from glucose, $\mathrm{Zn}$-SC, Al-SC, and Ni-SC provided yields of 85.1, 84.4 , and $32.8 \%$, respectively. The reason for the difference is that the acidity provided by specie $\mathrm{Ni}$ - is lower than $\mathrm{Zn}$ - and $\mathrm{Al}-$. A recent study also confirmed that the type of Lewis acids affects the yield of EMF (He et al., 2022). Meanwhile, this study found that the performance of the catalyst was also affected by the number of metal species in it. Specifically, the more types of metals contained in the catalyst, the better the catalytic efficiency. In addition, choosing a suitable ratio of Brønsted/ Lewis acid can improve the selectivity of EMF (Srinivasa Rao et al., 2020). For the ratio of strong/weak acid, when the weak acid accounts for more, it is harmful to glucose isomerization, fructose dehydration, and HMF etherification, resulting in lower EMF selectivity. On the contrary, when more strong acids are present in the system, the generated EMF can be turned into EL by a ring-opening reaction or converted into humins (He et al., 2022). Therefore, the ratio of Brønsted/Lewis and strong/weak acids in the bifunctional acid catalysts are also critical for obtaining EMF from glucose.

\section{Reaction Conditions}

The selectivity of EMF is also affected by the reaction conditions, such as temperature, time, ultrasound, and co-solvent.

Obtaining EMF from glucose usually requires a higher temperature and longer reaction time (Srinivasa Rao et al., 2020; Wang et al., 2021). However, continuously increasing the reaction temperature and time leads to the decrease in the yield of EMF, which is due to the unstable EMF and easily converted to EL under high temperature and long time (Zheng et al., 2021). During the conversion of glucose to EMF, water may be produced due to dehydration and etherification, which makes the hydrolysis of HMF into LA inevitable in this system (Wang et al., 2021). Since the polar co-solvent limits the conversion of HMF to LA (Morales et al., 2017), such as dimethyl sulfoxide (DMSO), tetrahydrofuran (THF), and GVL, many studies add cosolvents to this system, which significantly inhibited the production of EL (Yu et al., 2018). The amount of cosolvent also affects the yield of EMF. With the increase of co-solvent ratio, the yield of EMF first increased and then decreased, while the yield of EL continued to decrease and HMF continued to increase (He et al., 2022). The increase of
EMF can be attributed to the inhibition of the conversion of EMF to EL. Then adding too much co-solvent can reduce the amount of EMF, which is attributed to the decrease of ethanol content in the system to limit the etherification of HMF into EMF (Chen et al., 2020b). Besides, several studies have shown that ultrasonic assistance can form cavitation bubbles in the system and promote bond breakage, which can promote the reaction to a certain extent (Karnjanakom and Maneechakr, 2019b). The ultrasound assistance can greatly reduce the requirement of temperature and time from glucose to high yield EMF, such as $98^{\circ} \mathrm{C}$ for 47 min obtained $80.9 \%$ yield (Karnjanakom et al., 2020) and $106^{\circ} \mathrm{C}$ for $72 \mathrm{~min}$ obtained $86.3 \%$ yield (Karnjanakom and Maneechakr, 2019a). Therefore, EMF can be generated rapidly under mild conditions.

\section{CONCLUSION}

The richness, versatility, and accessibility of LCB are the reasons for its advantages in the field of sustainable energy conversion. The mechanisms and technologies of EMF production from LCBderived sugars in recent years were reviewed. These studies aim to develop more efficient catalysts and reaction systems to increase the yield of EMF.

Glucose as a typical LCB-derived sugar is used to synthesize EMF. It is mainly through path I (Figure 1) to synthesize EMF. In general, it shows low EMF yield when used monofunctional acid catalysts. The key to this problem is attributed to the glucose isomerization step (corresponding to Lewis acid) and low concentration of $\left[\mathrm{C}_{2} \mathrm{H}_{5} \mathrm{OH}_{2}\right]^{+}$ (corresponding to Brønsted acid). Yet, the developed bifunctional (Brønsted-Lewis) acid catalysts can effectively solve this problem, which can obtain satisfactory EMF yields from glucose. Meanwhile, the species of Lewis acids, ratio of Brønsted/Lewis acids, and ratio of strong/weak acids in the bifunctional acid catalysts have decisive effects on EMF yield. In addition, the optimization of reaction conditions has also made efforts in EMF yield. The suitable time, temperature, and a certain concentration of co-solvent can provide upside space for the selectivity of EMF.

\section{PERSPECTIVES}

Although there are some technological breakthroughs in obtaining high EMF yield from glucose, high yield EMF has not been found directly from LCB. However, studies based on glucose can provide feasible strategies for direct conversion of LCB to obtain high EMF in the future. Firstly, the bifunctional acid solid catalysts were given priority in the choice of catalysts, and the catalysts can adjust the type and quantity of acid. Secondly, it is also crucial to select appropriate co-solvents and reaction conditions. Although the ultrasound-assisted method showed excellent effects, it is not suitable for largescale industries. Therefore, it is of great significance to develop an efficient catalyst strategy to convert LCB into EMF under mild conditions. 


\section{AUTHOR CONTRIBUTIONS}

XL and DY jointly conceived the article, discussed the outline. DY wrote the manuscript. XL and HL have made preliminary revisions to the manuscript. $\mathrm{CL}$ and $\mathrm{XL}$ coordinated the entire content of the manuscript and made detailed revisions.

\section{REFERENCES}

Abraham, A., Mathew, A. K., Park, H., Choi, O., Sindhu, R., Parameswaran, B., et al. (2020). Pretreatment Strategies for Enhanced Biogas Production from Lignocellulosic Biomass. Bioresour. Technology. 301, 122725. doi:10.1016/ j.biortech.2019.122725

Bai, Y., Wei, L., Yang, M., Chen, H., Holdren, S., Zhu, G., et al. (2018). Three-Step Cascade over a Single Catalyst: Synthesis of 5-(ethoxymethyl)Furfural from Glucose over a Hierarchical Lamellar Multi-Functional Zeolite Catalyst. J. Mater. Chem. A. 6, 7693-7705. doi:10.1039/c8ta01242c

Bhatia, S. K., Jagtap, S. S., Bedekar, A. A., Bhatia, R. K., Patel, A. K., Pant, D., et al. (2020). Recent Developments in Pretreatment Technologies on Lignocellulosic Biomass: Effect of Key Parameters, Technological Improvements, and Challenges. Bioresour. Technology. 300, 122724. doi:10.1016/ j.biortech.2019.122724

Bredihhin, A., Mäeorg, U., and Vares, L. (2013). Evaluation of Carbohydrates and Lignocellulosic Biomass from Different wood Species as Raw Material for the Synthesis of 5-bromomethyfurfural. Carbohydr. Res. 375, 63-67. doi:10.1016/ j.carres.2013.04.002

Bredihhin, A., Vares, L., and Luiga, S. (2016). Application of 5ethoxymethylfurfural (EMF) for the Production of Cyclopentenones. Synthesis. 48, 4181-4188. doi:10.1055/s-0035-1562790

Chen, B., Xu, G., Zheng, Z., Wang, D., Zou, C., and Chang, C. (2019). Efficient Conversion of Corn stover into 5-ethoxymethylfurfural Catalyzed by Zeolite USY in Ethanol/THF Medium. Ind. Crops Prod. 129, 503-511. doi:10.1016/ j.indcrop.2018.12.027

Chen, B., Yan, G., Chen, G., Feng, Y., Zeng, X., Sun, Y., et al. (2020). Recent Progress in the Development of Advanced Biofuel 5-ethoxymethylfurfural. BMC Energy 2, 1-13. doi:10.1186/s42500-020-00012-5

Chen, Y., Guan, W., Zhang, Y., Yan, C., Li, B., Wei, Y., et al. (2020a). One-pot Synthesis of the Biofuel 5-ethoxymethylfurfural from Carbohydrates Using a Bifunctional Catalyst Prepared through a Pickering HIPE Template and PoreFilled Strategy. Energy Fuels. 34, 14264-14274. doi:10.1021/ acs.energyfuels.0c02942

Chen, Y., Peng, L., Zhang, J., and He, L. (2020b). Synergy of Al2(SO4)3 and H3PO4 in Co-Solvents Converts Starch to 5-Ethoxymethylfurfural. Catal. Commun. 137, 105947. doi:10.1016/j.catcom.2020.105947

Climent, M. J., Corma, A., and Iborra, S. (2014). Conversion of Biomass Platform Molecules into Fuel Additives and Liquid Hydrocarbon Fuels. Green. Chem. 16, 516. doi:10.1039/c3gc41492b

Corma, A., Iborra, S., and Velty, A. (2007). Chemical Routes for the Transformation of Biomass into Chemicals. Chem. Rev. 107, 2411-2502. doi:10.1021/cr050989d

Dai, J., Liu, Z., Hu, Y., Liu, S., Chen, L., Qi, T., et al. (2019). Adjusting the Acidity of Sulfonated Organocatalyst for the One-Pot Production of 5ethoxymethylfurfural from Fructose. Catal. Sci. Technol. 9, 483-492. doi:10.1039/c8cy02010h

De, S., Dutta, S., and Saha, B. (2012). One-pot Conversions of Lignocellulosic and Algal Biomass into Liquid Fuels. ChemSusChem. 5, 1826-1833. doi:10.1002/ cssc. 201200031

Dutta, S., De, S., Alam, M. I., Abu-Omar, M. M., and Saha, B. (2012). Direct Conversion of Cellulose and Lignocellulosic Biomass into Chemicals and Biofuel with Metal Chloride Catalysts. J. Catal. 288, 8-15. doi:10.1016/ j.jcat.2011.12.017

Guo, H., Duereh, A., Hiraga, Y., Aida, T. M., Qi, X., and Smith, R. L. (2017). Perfect Recycle and Mechanistic Role of Hydrogen Sulfate Ionic Liquids as Additive in Ethanol for Efficient Conversion of Carbohydrates into 5-

\section{FUNDING}

This work was financially supported by the scientific research funds of Guiyang University (GYU-KY-(2022)), the Guizhou Provincial Key Laboratory for Rare Animal and Economic Insects of the Mountainous Region ((2018)5102), and the National Natural Science Foundation of China (22065004).

ethoxymethylfurfural. Chem. Eng. J. 323, 287-294. doi:10.1016/ j.cej.2017.04.111

Guo, H., Duereh, A., Hiraga, Y., Qi, X., and Smith, R. L. (2018). Mechanism of Glucose Conversion into 5-ethoxymethylfurfural in Ethanol with Hydrogen Sulfate Ionic Liquid Additives and a Lewis Acid Catalyst. Energy Fuels. 32, 8411-8419. doi:10.1021/acs.energyfuels.8b00717

Hafizi, H., Walker, G., Iqbal, J., Leahy, J. J., and Collins, M. N. (2020). Catalytic Etherification of 5-Hydroxymethylfurfural into 5-Ethoxymethyfurfural over Sulfated Bimetallic SO42-/Al-Zr/KIT-6, a Lewis/Brønsted Acid Hybrid Catalyst. Mol. Catal. 496, 111176. doi:10.1016/j.mcat.2020.111176

He, Y., Zhang, L., Liu, Y., Yi, S., Yu, H., Zhu, Y., et al. (2022). Sulfated Complex Metal Oxides Solid Acids with Dual Brønsted-Lewis Acidic Property for Production of 5-Ethoxymethylfurfural from Biomass-Derived Carbohydrates. Chem. Eng. J. 429, 132279. doi:10.1016/j.cej.2021.132279

Jadhav, H., Pedersen, C. M., Sølling, T., and Bols, M. (2011). 3-Deoxy-glucosone Is an Intermediate in the Formation of Furfurals from D-Glucose. ChemSusChem. 4, 1049-1051. doi:10.1002/cssc.201100249

Jadhav, H., Taarning, E., Pedersen, C. M., and Bols, M. (2012). Conversion of D-Glucose into 5-hydroxymethylfurfural (HMF) Using Zeolite in [Bmim] Cl or Tetrabutylammonium Chloride (TBAC)/CrCl2. Tetrahedron Lett. 53, 983-985. doi:10.1016/j.tetlet.2011.12.059

Karnjanakom, S., and Maneechakr, P. (2019a). Designs of Linear-Quadratic Regression Models for Facile Conversion of Carbohydrate into High Value (5-(ethoxymethyl)furan-2-Carboxaldehyde) Fuel Chemical. Energ. Convers. Management. 196, 410-417. doi:10.1016/j.enconman.2019.06.015

Karnjanakom, S., and Maneechakr, P. (2019b). Novelty Catalytic Transformation of Sugar over Excellent Biphasic-Heterogeneous Reaction System. Catal. Commun. 130, 105767. doi:10.1016/j.catcom.2019.105767

Karnjanakom, S., Phanthong, P., Bayu, A., Maneechakr, P., Samart, C., Kongparakul, S., et al. (2020). Facile In Situ 5-EMF Synthesis and Extraction Processes from Catalytic Conversion of Sugar under Sustainable Long-Life Cycle. ACS Sustainable Chem. Eng. 8, 14867-14876. doi:10.1021/ acssuschemeng.0c04517

Lew, C. M., Rajabbeigi, N., and Tsapatsis, M. (2012). One-pot Synthesis of 5(ethoxymethyl)furfural from Glucose Using Sn-BEA and Amberlyst Catalysts. Ind. Eng. Chem. Res. 51, 5364-5366. doi:10.1021/ie2025536

Li, G., Pidko, E. A., and Hensen, E. J. M. (2014). Synergy between Lewis Acid Sites and Hydroxyl Groups for the Isomerization of Glucose to Fructose over SnContaining Zeolites: A Theoretical Perspective. Catal. Sci. Technol. 4, 2241-2250. doi:10.1039/c4cy00186a

Li, H., Riisager, A., Saravanamurugan, S., Pandey, A., Sangwan, R. S., Yang, S., et al. (2017). Carbon-increasing Catalytic Strategies for Upgrading Biomass into Energy-Intensive Fuels and Chemicals. ACS Catal. 8, 148-187. doi:10.1021/ acscatal.7b02577

Li, H., Saravanamurugan, S., Yang, S., and Riisager, A. (2016). Direct Transformation of Carbohydrates to the Biofuel 5-ethoxymethylfurfural by Solid Acid Catalysts. Green. Chem. 18, 726-734. doi:10.1039/c5gc01043h

Li, H., Wang, C., Xu, Y., Yu, Z., Saravanamurugan, S., Wu, Z., et al. (2020). Heterogeneous (de)Chlorination-Enabled Control of Reactivity in the LIquidPhase Synthesis of Furanic Biofuel From Cellulosic Feedstock. Green. Chem. 22, 637-645. doi:10.1039/c9gc04092g

Liu, B., Zhang, Z., Huang, K., and Fang, Z. (2013). Efficient Conversion of Carbohydrates into 5-ethoxymethylfurfural in Ethanol Catalyzed by $\mathrm{AlCl} 3$. Fuel. 113, 625-631. doi:10.1016/j.fuel.2013.06.015

Liu, B., and Zhang, Z. (2013). One-pot Conversion of Carbohydrates into 5ethoxymethylfurfural and Ethyl D-Glucopyranoside in Ethanol Catalyzed by a Silica Supported Sulfonic Acid Catalyst. RSC Adv. 3, 12313. doi:10.1039/ c3ra41043a 
Liu, S., Meng, Y., Li, H., and Yang, S. (2021). Hierarchical Porous MIL-101(Cr) Solid Acid-Catalyzed Production of Value-Added Acetals from BiomassDerived Furfural. Polymers. 13, 3498. doi:10.3390/polym13203498

Mascal, M., and Nikitin, E. B. (2008). Direct, High-Yield Conversion of Cellulose into Biofuel. Angew. Chem. 120, 8042-8044. doi:10.1002/ anie. 200801594

Morales, G., Paniagua, M., Melero, J. A., and Iglesias, J. (2017). Efficient Production of 5-ethoxymethylfurfural from Fructose by Sulfonic Mesostructured Silica Using DMSO as Co-solvent. Catal. Today. 279, 305-316. doi:10.1016/ j.cattod.2016.02.016

Pan, H., Li, H., Zhang, H., Wang, A., and Yang, S. (2020). Functional Nanomaterials-Catalyzed Production of Biodiesel. Cnano. 16, 376-391. doi:10.2174/1573413715666190411142820

Rackemann, D. W., and Doherty, W. O. (2011). The Conversion of Lignocellulosics to Levulinic Acid. Biofuels, Bioprod. Bioref. 5, 198-214. doi:10.1002/bbb.267

Rajabbeigi, N., Torres, A. I., Lew, C. M., Elyassi, B., Ren, L., Wang, Z., et al. (2014). On the Kinetics of the Isomerization of Glucose to Fructose Using Sn-Beta. Chem. Eng. Sci. 116, 235-242. doi:10.1016/j.ces.2014.04.031

Ras, E.-J., Maisuls, S., Haesakkers, P., Gruter, G.-J., and Rothenberg, G. (2009). Selective Hydrogenation of 5-ethoxymethylfurfural over Alumina-Supported Heterogeneous Catalysts. Adv. Synth. Catal. 351, 3175-3185. doi:10.1002/ adsc. 200900526

Ras, E.-J., McKay, B., and Rothenberg, G. (2010). Understanding Catalytic Biomass Conversion Through Data Mining. Top. Catal. 53, 1202-1208. doi:10.1007/ s11244-010-9563-z

Shrotri, A., Kobayashi, H., and Fukuoka, A. (2018). Cellulose Depolymerization over Heterogeneous Catalysts. Acc. Chem. Res. 51, 761-768. doi:10.1021/ acs.accounts.7b00614

Somerville, C., Youngs, H., Taylor, C., Davis, S. C., and Long, S. P. (2010). Feedstocks for Lignocellulosic Biofuels. Science. 329, 790-792. doi:10.1126/ science. 1189268

Srinivasa Rao, B., Dhana Lakshmi, D., Krishna Kumari, P., Rajitha, P., and Lingaiah, N. (2020). Dehydrative Etherification of Carbohydrates to 5ethoxymethylfurfural over SBA-15-Supported Sn-Modified Heteropolysilicate Catalysts. Sustainable Energ. Fuels. 4, 3428-3437. doi:10.1039/d0se00509f

Tan, J., Liu, Q., Chen, L., Wang, T., Ma, L., and Chen, G. (2017). Efficient Production of Ethyl Levulinate from Cassava over Al2(SO4)3 Catalyst in Ethanol-Water System. J. Energ. Chem. 26, 115-120. doi:10.1016/ j.jechem.2016.08.004

Tong, X., Ma, Y., and Li, Y. (2010). Biomass into Chemicals: Conversion of Sugars to Furan Derivatives by Catalytic Processes. Appl. Catal. A: Gen. 385, 1-13. doi:10.1016/j.apcata.2010.06.049

Wang, S., Chen, Y., Jia, Y., Xu, G., Chang, C., Guo, Q., et al. (2021). Experimental and Theoretical Studies on Glucose Conversion in Ethanol Solution to 5ethoxymethylfurfural and Ethyl Levulinate Catalyzed by a Brønsted Acid. Phys. Chem. Chem. Phys. 23, 19729-19739. doi:10.1039/d1cp02986j

Xiang, B., Wang, Y., Qi, T., Yang, H.-Q., and Hu, C.-W. (2017). Promotion Catalytic Role of Ethanol on Brønsted Acid for the Sequential DehydrationEtherification of Fructose to 5-ethoxymethylfurfural. J. Catal. 352, 586-598. doi:10.1016/j.jcat.2017.06.031
Xin, S., Wang, Q., Xu, J., Chu, Y., Wang, P., Feng, N., et al. (2019). The Acidic Nature of "NMR-Invisible" Tri-Coordinated Framework Aluminum Species in Zeolites. Chem. Sci. 10, 10159-10169. doi:10.1039/c9sc02634g

Xu, G., Chen, B., Zheng, Z., Li, K., and Tao, H. (2017). One-pot Ethanolysis of Carbohydrates to Promising Biofuels: 5-ethoxymethylfurfural and Ethyl Levulinate. Asia-pac. J. Chem. Eng. 12, 527-535. doi:10.1002/apj.2095

Yang, F., Tang, J., Ou, R., Guo, Z., Gao, S., Wang, Y., et al. (2019). Fully Catalytic Upgrading Synthesis of 5-ethoxymethylfurfural from Biomass-Derived 5hydroxymethylfurfural over Recyclable Layered-Niobium-Molybdate Solid Acid. Appl. Catal. B: Environ. 256, 117786. doi:10.1016/j.apcatb.2019.117786

Yang, Y., Hu, C.-w., and Abu-Omar, M. M. (2012). Conversion of Carbohydrates and Lignocellulosic Biomass into 5-hydroxymethylfurfural Using AlCl3.6H2O Catalyst in a Biphasic Solvent System. Green. Chem. 14, 509-513. doi:10.1039/ clgc15972k

Yu, D., Liu, X., Jiang, J., Liu, Y., Tan, J., Li, H., et al. (2021). Catalytic Synthesis of the Biofuel 5-ethoxymethylfurfural (EMF) from Biomass Sugars. J. Chem. 2021, 1-16. doi:10.1155/2021/9015481

Yu, X., Gao, X., Peng, L., He, L., and Zhang, J. (2018). Intensified 5ethoxymethylfurfural Production from Biomass Components over Aluminum-Based Mixed-Acid Catalyst in Co-solvent Medium. ChemistrySelect .3, 13391-13399. doi:10.1002/slct.201803059

Yu, X., Gao, X., Tao, R., and Peng, L. (2017). Insights into the Metal Salt Catalyzed 5-ethoxymethylfurfural Synthesis from Carbohydrates. Catalysts. 7, 182. doi:10.3390/catal7060182

Zeng, M., and Pan, X. (2020). Insights into Solid Acid Catalysts for Efficient Cellulose Hydrolysis to Glucose: Progress, Challenges, and Future Opportunities. Catal. Rev. 1, 1-46. doi:10.1080/01614940.2020.1819936

Zhang, J., Dong, K., Luo, W., and Guan, H. (2018). Catalytic Upgrading of Carbohydrates into 5-ethoxymethylfurfural Using SO3H Functionalized Hyper-Cross-Linked Polymer Based Carbonaceous Materials. Fuel. 234, 664-673. doi:10.1016/j.fuel.2018.07.060

Zheng, Z., Wang, C., Chen, Y., Wang, S., Guo, Q., Chang, C., et al. (2021). One-pot Efficient Conversion of Glucose into Biofuel 5-ethoxymethylfurfural Catalyzed by Zeolite Solid Catalyst. Biomass Conv. Bioref., 1-12. doi:10.1007/s13399-02101660-1

Conflict of Interest: The authors declare that the research was conducted in the absence of any commercial or financial relationships that could be construed as a potential conflict of interest.

Publisher's Note: All claims expressed in this article are solely those of the authors and do not necessarily represent those of their affiliated organizations, or those of the publisher, the editors and the reviewers. Any product that may be evaluated in this article, orclaim that may be made by its manufacturer, is not guaranteed or endorsed by the publisher.

Copyright (c) $2022 \mathrm{Liu}, \mathrm{Yu}$, Luo and Li. This is an open-access article distributed under the terms of the Creative Commons Attribution License (CC BY). The use, distribution or reproduction in other forums is permitted, provided the original author(s) and the copyright owner(s) are credited and that the original publication in this journal is cited, in accordance with accepted academic practice. No use, distribution or reproduction is permitted which does not comply with these terms. 